\title{
Late Follow-Up of Balloon Angioplasty in Children with a Native Coarctation of the Aorta
}

\author{
Alan M. Mendelsohn, MD, Thomas R. Lloyd, MD, Dennis C. Crowley, MD, \\ Satinder K. Sandhu, MD, Keith C. Kocis, MD, and Robert H. Beekman III, MD
}

\begin{abstract}
Between May 1984 and April 1993, 59 children underwent balloon angioplasty of a native coarctation at our institution. The follow-up protocol included a cardiac catheterization 1 to 2 years after angioplasty, which was performed in $\mathbf{9 0} \%$ of patients with $\geq 2$ years follow-up. Angioplasty caused an acute decrease in peak systolic gradient from $46 \pm 2$ to $15 \pm 2 \mathrm{~mm} \mathrm{Hg}$, without early aneurysm or emergent surgical intervention in any pationt. Based on follow-up data, a satisfactory result was obtained in 38 patients (64\%; $\mathbf{7 0} \%$ confidence limit: $\mathbf{5 8} \%$ to $\mathbf{7 1} \%$ ), defined as a residual systolic gradient $<20 \mathrm{~mm} \mathrm{Hg}$ and no aneurysm. In these patients the gradient decreased acutely from $43 \pm 2$ to $9 \pm 1 \mathrm{~mm} \mathrm{Hg}$, was $6 \pm 1 \mathrm{~mm} \mathrm{Hg}$ at follow-up catheterization, and $9 \pm 2 \mathrm{~mm} \mathrm{Hg}$ by clinical evaluation $4.4 \pm$ 0.3 years after angioplasty. Twenty-one patients (36\%; $70 \%$ confidence limit: $29 \%$ to $42 \%$ ) had an unsatisfactory result due to a residual gradient $\geq 20 \mathrm{~mm} \mathrm{Hg}(n=19)$ or aneurysm formation ( $=$ 3), or both. Restenosis occurred in 6 patients, and occurred more in infants than in children $\geq 12$ months of age (3 of 5 infants vs 3 of 41 children, $p=0.01$ ). Thus, balloon angioplasty provides an effective initial treatment strategy for native coarctation in most children aged $>12$ months.
\end{abstract}

(Am J Cardiol 1994;74:696-700)
$\mathrm{T}$ The choice of treatment for children with a native (unoperated) coarctation of the aorta is controversial. Several surgical procedures have been advocated since $1945,{ }^{1-4}$ each associated with a variable risk of restenosis ${ }^{5,6}$ or aneurysm formation. ${ }^{7-9}$ More recently, percutaneous balloon angioplasty has been investigated as a treatment option for native coarctation. ${ }^{10-15}$ Few studies, however, have reported systematic hemodynamic and angiographic follow-up data. Since 1984, we have performed balloon angioplasty in children with a native coarctation, and an elective left-sided catheterization 1 to 2 years after angioplasty as part of the follow-up protocol. In this report we review our experience with 59 children who underwent balloon angioplasty for a native coarctation at our institution between 1984 and 1993.

\section{METHODS}

Patients were eligible for balloon angioplasty if they had an anatomically discrete coarctation and a resting systolic pressure gradient of $\geq 25 \mathrm{~mm} \mathrm{Hg}$. Informed consent was obtained in all patients, and institutional review board approval was also obtained for procedures performed before 1990. Initially, infants aged $<12$ months were excluded. However, with the availability of smaller balloon catheters since 1988, the technique was extended to infants. Patients with a long-segment coarctation or an associated intracardiac lesion requiring concurrent surgical repair were excluded.

The technique used for balloon angioplasty has been reported previously. ${ }^{15}$ An angioplasty balloon is selected to achieve a balloon-to-isthmus diameter ratio of approximately 1.0. Fifty-eight of 59 procedures were performed using a retrograde single-balloon technique; a double-balloon technique was used in 1 patient. All patients underwent systemic heparinization $(100 \mathrm{U} / \mathrm{kg}$; maximum 3,000 U). The angioplasty balloon was inflated by hand for 5 to 10 seconds until relief of the stenotic waist was noted; balloon inflation pressures were not monitored. Hemodynamic measurements and biplane aortic angiography were performed immediately before and after coarctation angioplasty.

Follow-up evaluation: Repeat angiography and cath-

From the Division of Pediatric Cardiology, Department of Pediatrics, C. S. Mott Children's Hospital, University of Michigan Medical Center, Ann Arbor, Michigan. This study was supported by Grant 3MO1 RR00042 from the General Clinical Research Center, Bethesda, Maryland. Dr. Mendelsohn is supported by National Research Service Award IIL08709-01 from the National Heart, Lung, and Blood Institutc, National Institutes of Health, Bethesda, Maryland. Manuscript received December 22, 1994; revised manuscript received April 11, 1994, and accepted April 12.

Address for reprints: Robert H. Beekman III, MD, Division of Pediatric Cardiology, University of Michigan Medical Center, F1310, Box 0204, Ann Arbor, Michigan 48109-0204. eter measurement of the residual gradient were routinely performed 1 to 2 years after balloon angioplasty. This follow-up catheterization has been performed in 43 of 48 patients $(90 \%)$ with $\geq 2$ years of follow-up (mean 1.7 \pm 0.2 ). Patients were also evaluated as outpatients on an annual basis. Blood pressure was measured in the right arm and in the leg contralateral to the side used for angioplasty. Chest radiography was performed annually to screen for mediastinal widening suggestive of an aortic 
aneurysm. Previous investigations have found the chest radiograph to be $100 \%$ sensitive in screening for aortic aneurysms after surgical repair of coarctation. ${ }^{6}$

In almost all patients, the presence or absence of an aortic aneurysm was determined by angiography. An aneurysm was defined as a saccular outpouching, or a fusiform dilation with a ratio of its diameter to the descending aorta diameter of $\geq 1.5 .6 .9$ In patients who had not yet undergone a follow-up aortogram, screening for aneurysms was performed by review of the aortogram obtained immediately after balloon angioplasty and by review of the most recent chest radiograph.

Statistical analysis: Data are expressed as mean values \pm 1 SEM. The 2-tailed group Student's $t$ test and Fisher's exact test were performed to compare continuous and categorical data. Repeated measures analysis of variance was used to evaluate serial changes in continuous measures. Univariate analyses were performed to identify potential factors influencing angioplasty outcome. Age and weight at procedure, gradient, isthmus diameter, balloon diameter, balloon-to-isthmus diameter ratio, and the presence of the Turner syndrome or a patent ductus arteriosus were cvaluated as potential predictors of outcome. Statistical significance was accepted at $\mathbf{p}<0.05$ using the Scheffe test to correct for multiple comparisons.

\section{RESULTS}

Acute data: Between May 1984 and April 1993, 59 children ( 36 males and 23 females) underwent balloon angioplasty for a native coarctation. Their mean age was $6.0+0.6$ years (range 0.1 to 19) and mean weight was $23.9 \pm 2.3 \mathrm{~kg}$ (range 4.4 to 81.5 ); 6 infants were $<12$ months of age. Seven patients had Turner syndrome. The balloon-to-isthmus diameter ratio was $1.03 \pm 0.02$ (range 0.7 to 1.3 ). Angioplasty decreased the systolic gradient acutely, from $46 \pm 2$ to $15 \pm 2$ Inm $\mathrm{Hg}(p=0.001)$. Fortysix patients $(78 \%)$ had an immediate reduction in gradient to $<20 \mathrm{~mm} \mathrm{Hg}$. The ascending aorta systolic pressure decreased from $135 \pm 2$ to $125 \pm 2 \mathrm{~mm} \mathrm{Hg}$ ( $\mathrm{p}=$ 0.001 ), and the descending aorta systolic pressure increased from $89 \pm 2$ to $110 \pm 2 \mathrm{~mm} \mathrm{Hg}(\mathrm{p}=0.001$ )

Acute complications: There were no deaths, no aneurysms identified acutely, no aortic tears or perforations requiring surgical intervention, and no episodes of paradoxical hypertension. One cerebrovascular accident occurred during the first coarctation angioplasty performed at this institution in 1984. ${ }^{15}$ The event was thought to be thromboembolic, related to inadequate anticoagulation. One patient required a transfusion for femoral artery hemorrhage, and 6 patients had an absent lower extremity pulse treated successfully with intravenous heparin. All children were discharged home within 24 to 48 hours of the procedure.

Follow-up data: Based on follow-up data, patients were divided into 2 outcome groups, defined by the magnitude of the residual coarctation gradient (at the most recent evaluation) and the presence or absence of an aortic aneurysm (Table I). Thirty-eight patients (group A) were classified as having a satisfactory outcome, defined as a residual systolic gradient $<20 \mathrm{~mm} \mathrm{Hg}$ and no aortic aneurysm. Twenty-one patients (group B) had an
TABLE I Clinical and Hemodynamic Data in Patients With (Group A) and Without (Group B) a Satisfactory Outcome After Balloon Angioplasty of a Native Coarctation

\begin{tabular}{|c|c|c|c|}
\hline & $\begin{array}{l}\text { Group A } \\
(n=38)\end{array}$ & $\begin{array}{l}\text { Group B } \\
(n=21)\end{array}$ & $p$ Value \\
\hline Age (years) & $70+08$ & $4.4 \pm 0.7$ & 0.03 \\
\hline Weight (kg) & $27.7 \pm 3.2$ & $17.4 \pm 2.1$ & 0.02 \\
\hline $\begin{array}{l}\text { Balloon/isthmus } \\
\text { diameter ratio }\end{array}$ & $1.04 \pm 0.03$ & $1.03 \pm 0.04$ & NS \\
\hline \multicolumn{4}{|l|}{ Acute data } \\
\hline $\begin{array}{l}\text { Pre-BA gradient } \\
\qquad(\mathrm{mm} \mathrm{Hg})\end{array}$ & $43.3 \pm 2.2$ & $50.2 \pm 2.3$ & 0.04 \\
\hline $\begin{array}{l}\text { Post-BA gradient } \\
\text { (acute, } \mathrm{mm} \mathrm{Hg} \text { ) }\end{array}$ & $9.3 \pm 1.1$ & $25.6 \pm 2.0$ & 0.001 \\
\hline \multicolumn{4}{|l|}{ Cath. follow-up data } \\
\hline $\begin{array}{l}\text { Time to cath. } \\
\text { follow-up (years) }\end{array}$ & $1.5 \pm 0.1$ & $2.0 \pm 0.6$ & NS \\
\hline $\begin{array}{l}\text { Follow-up cath. } \\
\text { gradient }(\mathrm{mm} \mathrm{Hg})\end{array}$ & $6.0 \pm 1.3$ & $27.4 \pm 4.4$ & 0.001 \\
\hline Aortic aneurysm (no.) & 0 & 3 & - \\
\hline \multicolumn{4}{|l|}{ Clinical follow-up data } \\
\hline $\begin{array}{l}\text { Time to clinical } \\
\text { follow-tsp (years) }\end{array}$ & $4.4 \pm 0.3$ & $3.9 \pm 0.4$ & NS \\
\hline $\begin{array}{l}\text { Follow-up clinical } \\
\text { gradient }(\mathrm{mm} \mathrm{Hg})\end{array}$ & $9.2 \pm 1.8$ & $28.6 \pm 4.1$ & 0.001 \\
\hline \multicolumn{4}{|c|}{$\begin{array}{l}\text { Values are expressed as mean } \pm \text { SEM. } \\
B A=\text { balloon angioplasty: Cath. = cardiac catheterization; NS = not } \\
\text { significant. }\end{array}$} \\
\hline
\end{tabular}

unsatisfactory outcome due to a residual systolic gradient $\geq 20 \mathrm{~mm} \mathrm{Hg}(n=18)$ or an aortic aneurysm $(n=2)$, or both $(n=1)$.

Group A: Thirty-eight of the 59 patients $(64 \% ; 70 \%$ confidence limit [CL]: $58 \%$ to $71 \%$ ) had a satisfactory outcome after angioplasty. The systolic gradient in group A decreased acutely from $43 \pm 2$ to $9 \pm 1 \mathrm{~mm} \mathrm{Hg}$. Thirty-one of these patients $(82 \%)$ have undergone followup catheterization and angiography $1.5 \pm 0.1$ years after balloon angioplasty (Figure 1). The remaining patients have not yet been scheduled for the follow-up study. At follow-up catheterization, the residual gradient was $6 \pm$ $1 \mathrm{~mm} \mathrm{Hg}$, and there were no aortic aneurysms. Longer term clinical evaluation ( $4.4 \pm 0.3$ years) revealed a gradient of $9 \pm 2 \mathrm{~mm} \mathrm{Hg}$ in these patients (Figure 2). No patient in group A has had evidence of late aneurysm
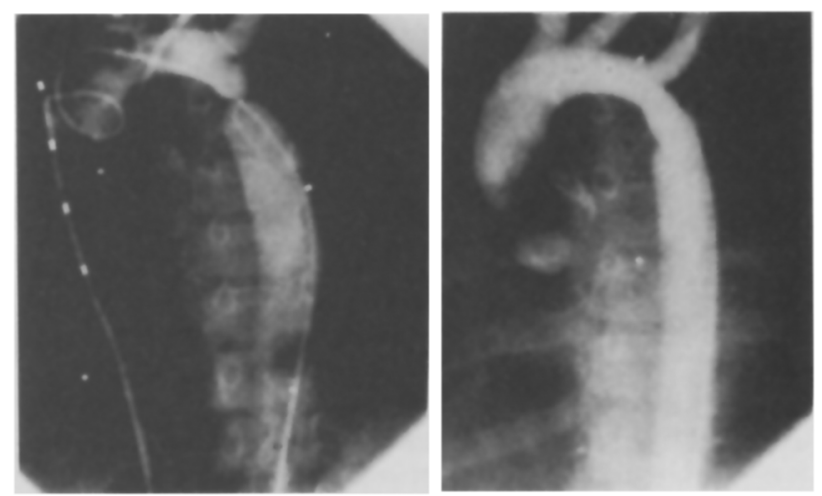

FIGURE 1. Aortogram before (left panel) and 2 years after (right panel) balloon angloplasty in a 3-year-old girl with a native coarctation of the aorta. Peak systolic pressure gradient was reduced immediately, from 72 to $15 \mathrm{~mm}$ Hg. At follow-up 2 years later the residual gradient was $6 \mathrm{~mm} \mathrm{Hg}$, and there was no evidence of an aortic aneurysm. 
formation by chest radiography, upper extremity hypertension, or lower extremity claudication.

Group B: Twenty-one patients (36\%; 70\% CL: $29 \%$ to $42 \%$ ) had an unsatisfactory outcome after angioplasty. Nineteen had a residual gradient $\geq 20 \mathrm{~mm} \mathrm{Hg}$, and 3 patients had an aneurysm at the dilation site. The systolic gradient in group B decreased acutely from $50 \pm 2$ to $26 \pm 2 \mathrm{~mm} \mathrm{Hg}$. A repeat cardiac catheterization was performed in 12 group B patients $2.0 \pm 0.6$ years after balloon angioplasty ( 8 patients underwent surgical repair of a residual coarctation without follow-up catheterization). The follow-up study revealed a residual gradient of $27 \pm 4 \mathrm{~mm} \mathrm{Hg}(\mathrm{p}=$ NS vs gradient immediately after angioplasty). Thus, in these 12 patients there was no significant remodeling of the coarctation dilation site at follow-up.

Restenosis: In 13 of the 19 group B patients with a residual gradient $\geq 20 \mathrm{~mm} \mathrm{Hg}$, inadequate gradient reduction was noted immediately after angioplasty. Six patients in group B had satisfactory gradient reduction acutely (i.e., gradient $<20 \mathrm{~mm} \mathrm{Hg}$ ), but exhibited restenosis at follow-up (defined as a change in status from satisfactory to unsatisfactory gradient reduction). The median age of these 6 patients was 4 months (range 5 weeks to 6.1 years) and the median weight was $5.6 \mathrm{~kg}$ (range 4.7 to $24 \mathrm{~kg}$ ). The balloon-to-isthmus diameter ratio was $1.03 \pm 0.02$. In these 6 patients, angioplasty caused an acute reduction in systolic gradient, from 49 \pm 5 to $14 \pm 2 \mathrm{~mm} \mathrm{Hg}$ (range 8 to 18 ). However, an increase in residual gradient to $37 \pm 4 \mathrm{~mm} \mathrm{Hg}$ (range 25 to $50 ; \mathrm{p}<0.05$ ) was documented at follow-up a median of 1.1 years (range 1 week to 6 years) after angioplasty. All cases of restenosis were anatomically discrete, and unrelated to arch hypoplasia (Figure 3). Restenosis occurred in $60 \%$ ( 3 of 5) of infants aged $<12$ months compared with $7.3 \%$ ( 3 of 41 ) of patients aged $>12$

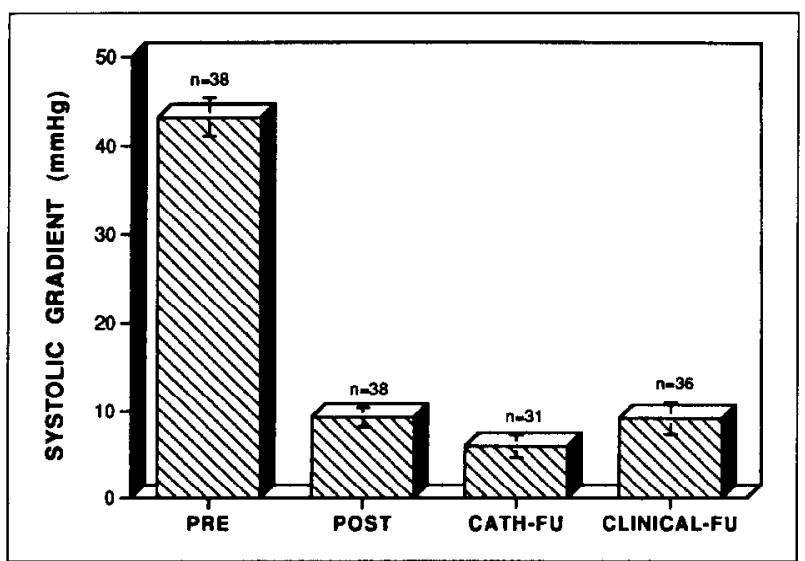

FIGURE 2. Peak systolic pressure gradients of patients in group $A$ before and after coarctation angioplasty, and at follow-up. The gradient decreased acutoly from 43 to $9 \mathrm{~mm} \mathrm{Hg}$, and remained unchanged by clinical follow-up 4.4 years later. The 3 values after angioplasty are signifieantly less than the gradient before angioplasty (p $<0.05 ; p=$ NS for other pairwise comparisons). CATH-FU = follow-up gradient at cardiac catheterization $1.5 \pm 0.1$ yoars after angioplasty; CLINICAL-FU = follow-up gradient by cuff measurement $4.4 \pm 0.3$ years after angioplasty; POST = immediately after angloplasty; PRE = immediately before angioplasty. months at angioplasty $(p=0.01)$. Two patients underwent a successful second balloon angioplasty, and 4 underwent surgical repair of the recurrent coarctation.

Aortic aneurysm: An aneurysm at the dilation site has been identified in 3 patients (5.1\%; 70\% CL: $2.8 \%$ to $8.9 \%$ ). These children ranged in age from 4.4 to 8.4 years at angioplasty, and none had Turner syndrome. The balloon-to-isthmus diameter ratio ranged from 1.1 to 1.2 . All 3 aneurysms were saccular, and all were first identified by follow-up angiography. One patient underwent surgical resection of the aneurysm and an associated residual coarctation. ${ }^{16}$ The remaining 2 patients have been followed by serial angiography 2 and 6 years after aneurysm identification. In each case the small saccular aneurysm has not changed in size (Figure 4 ).

Fourteen of the 21 patients in group B have undergone successful elective surgical repair. The outcome and histologic findings in 11 of these cases have been reported previously. ${ }^{16}$ There have been no operative deaths, no episodes of paresis, no severe postoperative hemorrhage, and no paradoxical hypertension. All patients have had a satisfactory outcome.

Comparison of groups A and B (Table I): There was a significant difference between groups $A$ and $B$ in agc ( $7.0 \pm 0.8$ vs $4.4 \pm 0.7$ years, $p=0.03)$, weight $(27.7 \pm$ 3.2 vs $17.4 \pm 2.1 \mathrm{~kg}, \mathrm{p}=0.02$ ), and systolic gradient before balloon angioplasty ( $43 \pm 2$ vs $50 \pm 2 \mathrm{~mm} \mathrm{Hg}$, $\mathrm{p}=0.04)$. There was no difference between the groups in the balloon-to-isthmus diameter ratio $(1.04 \pm 0.03 \mathrm{vs}$ $1.03 \pm 0.04)$, isthmus diameter, and prevalence of patent ductus arteriosus or of Turner syndrome.

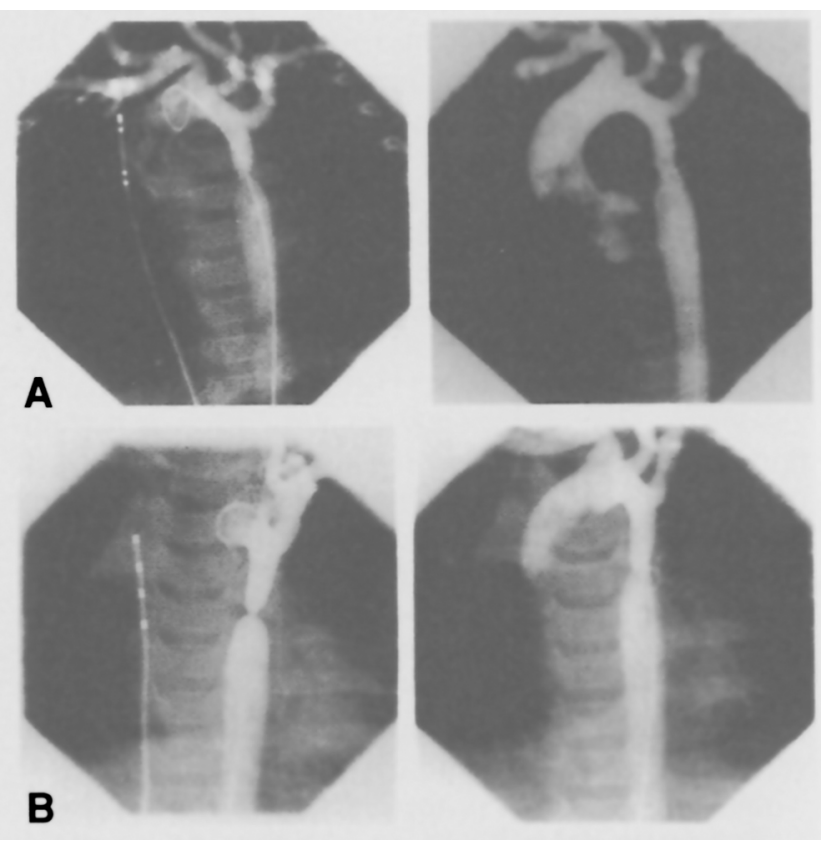

FIGURE 3. A, aortogram before (left panel) and immediately after (right panel) balloon angioplasty in a 4 month-old infant with a native coarctation of the aorta. Peak systolic pressure gradient was reduced immediateIy, from 54 to $8 \mathrm{~mm} \mathrm{Hg}$. B, repeat study 9 months after angioplasty documented restenosis, with a discrete recurrent coarctation (left panel). The recurrent gradient of $45 \mathrm{~mm} \mathrm{Hg}$ was reduced to $15 \mathrm{~mm} \mathrm{Hg}$ after a repeat balloon angioplasty procodure (right panel). 


\section{DISCUSSION}

These data are consistent with previous studies ${ }^{11-14}$ demonstrating the effectiveness of balloon angioplasty in most children with a native coarctation. During a 9year experience at our institution, $64 \%$ of patients have had a satisfactory angioplasty result (Figure 2); these patients have a residual gradient of $9 \mathrm{~mm} \mathrm{Hg}(6 \mathrm{~mm} \mathrm{Hg}$ by catheterization), no upper extremity hypertension, and no aortic aneurysm. Children with a satisfactory outcome were older and had a lower initial coarctation gradient than children with an unsatisfactory outcome. Coarctation restenosis occurred frequently when angioplasty was performed in infants aged $<12$ months, but seldom occurred in older children. A $5 \%$ incidence of aneurysm formation was identified by follow-up angiography.

Coarctation restenosis: Restenosis appears to occur often when coarctation angioplasty is performed in infancy. ${ }^{17}$ We identified a $60 \%$ ( 3 of 5 ) incidence of restenosis after an initially successful angioplasty in infants aged $<12$ months compared with an incidence of $7.3 \%$ ( 3 of 41 ) in children aged $>12$ months at angioplasty $(\mathrm{p}=0.01)$. However, only 6 infants $<12$ months of age underwent angioplasty, a limitation of the present series. In a larger infant experience, Lababidi ${ }^{12}$ documented coarctation restenosis in 15 of 21 infants $<3$ months of age at angioplasty. Eight of these children underwent successful repeat balloon angioplasty, and 7 underwent surgical repair of the recurrent coarctation. $\mathrm{Rao}^{13}$ reported restenosis in 3 of 17 infants who were reevaluated 6 to 22 months after angioplasty of a native coarctation. Thus, data from several centers suggest that restenosis is common after coarctation angioplasty in infancy, as is the case with surgical repair. 5.7

Aneurysm formation: Aneurysm formation has been reported previously after coarctation angioplasty. ${ }^{11-15.18 .19}$ In the 2 largest series, ${ }^{11.12}$ the incidence of aneurysm formation has varied from $1.8 \%$ to $5.7 \%$, similar to the incidence of $5.1 \%$ in the present series. Early reports in smaller series, however, noted incidence rates of aneurysm formation as high as $42 \%$ after coarctation angioplasty. ${ }^{18.19}$ There are several possible explanations to reconcile the discrepant rates of aneurysm formation that have been reported. First, different angioplasty techniques may have been used. We used a balloon-to-isthmus diameter ratio of 1.0. This conservative balloon choice

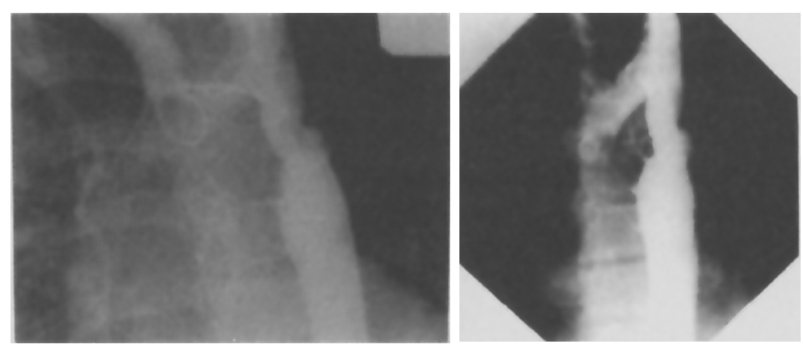

FIGURE 4. Serial aortograms showing a saccular aneurysm at the dilation site in a 16-year-old boy after balloon angioplasty of a native coarctation. The aneurysm was first identified by angiography 1 year after angioplasty (left panel). Follow-up angiogram 6 years later (right panel) showed no change in the size of the aneurysm (when corrected for differences in image magnification). may partially explain the relatively low rate of aneurysm formation in this series. Second, the definition of an aneurysm may vary. We defined an aneurysm as either a saccular outpouching or a fusiform dilation whose diameter is $\geq 1.5$ times the diameter of the descending aorta. This definition has also been prospectively applied to patients after patch aortoplasty repair of coarctation in whom $24 \%$ were found to have an aortic aneurysm. ${ }^{6}$ Third, native anatomic irregularities in the aortic contour may be mistaken for an aneurysm. ${ }^{20}$ This is particularly true immediately distal to a coarctation where angiography may provide poor anatomic delineation before angioplasty. Angiograms before angioplasty must be carefully studied to avoid the misdiagnosis of a postangioplasty aneurysm.

Peripheral vascular injury: Burrows et $\mathrm{al}^{21}$ reported a 45\% (29 of 64) incidence of iliofemoral arterial complications after balloon coarctation angioplasty or aortic valvuloplasty in children. However, high-profile 8 to $9 \mathrm{Fr}$ balloon catheters were used in their study. They noted that since 1988, when smaller angioplasty catheters became available, no further serious arterial injury has been encountered. The incidence of clinically recognized femoral artery obstruction in our series was $10 \%$ ( 6 of $59 ; 70 \%$ CL: $6.8 \%$ to $15 \%$ ), with 6 patients requiring heparin for diminished pulses; none required surgical intervention. In 5 of these 6 patients, angioplasty was performed with relatively large catheters (before 1988), and all 6 children were $<2$ years of age. The incidence of femoral artery injury may be underestimated in this series because follow-up femoral angiography was not routinely performed. Nevertheless, it appears that the lower-profile angioplasty catheters currently available have reduced the risk of important femoral artery injury in children. We are still hesitant in performing coarctation angioplasty in early infancy, because loss of arterial access may compromise our future ability to perform angioplasty in this group of patients with a documented high rate of coarctation restenosis (regardless of the method of initial coarctation repair).

1. Gross RE, Hufnagel CA. Coarctation of the aorta: experimental studies regarding its surgical correction. $N$ Engl J Med 1945:233:287-293.

2. Crafoord C, Nylin G. Congenital coarctation of the aorta and its surgical treatment. I Thorac Surg 1945;14:347-361.

3. Vosschulte K. Isthmusplastik zur behandlung der aortem isthmus-stenose. Thoraxchirugie 1957;4:443-450.

4. Waldhausen JA, Nahrwold DL. Repair of coarctation of the aorta with a subclavian [lap. J Thorac Cardiovase Surg 1960:51:532-533.

5. Beekman RH, Rocchini AP. Behrendt DM, Rosenthal A. Reoperation for coaretation of the aorta. Am J Cardiol 1981:48:1 108-1114.

6. Bromberg BI, Beekman RH, Rocchini AP, Snider AR, Bank ER, Heidelberger K, Rosenthal A. Aortic aneurysm after patch aortoplasty repair of coarctation: prospective analysis of prevalence. screening tests and risks. I Am Coll Cardiol 1989:14:734-741.

7. Beckman RH, Rocchini AP. Behrendt DM, Bove EL, Dick M, Crowley DC, Snider $A R$. Rosenthal A. Long-term outcome after repair of coarctation in infancy: subclavian angioplasty does not reduce the need for reoperation. $J \mathrm{Am} \mathrm{Coll} \mathrm{Car}$ diol 1986;8:1406-1411

8. Martin MM, Beckman RH, Rocchini AP, Crowley DC Rosenthal A. Aortic aneurysms after subclavian flap angioplasty repair of coarctation of the aorta. Am J Cardiol 1988,61:951-953.

9. Mendelsohn AM, Crowley DC, Lindauer A, Beekman RH. Rapid progression of aortic aneurysms following patch aortoplasty repair of coarctation. I Am Coll Cardiol 1992:20:381-385.

10. Sos T, Sniderman KW. Rettek-Sos B. Strupp A. Alonso DR. Percutaneous transluminal dilatation of coarctation of thoracic aorta postmortem. Lancet 1979: 2:970) 971 .

11. Tynan M. Finley JP. Fontes V. Hess J. Kan J. Balloon angioplasty for the treat- 
ment of native coarctation: results of valvuloplasty and angioplasty of congenital anomalies registry. Am J Cardiol 1990;65:790-792.

12. Lababidi $Z$. Percutaneous balloon coarctation angioplasty: long-term results. $J$ Intervent Cardiol 1992;5:57-61.

13. Rao PS. Balloon angioplasty of aortic coarctation. Clin Cardiol 1989; 12:618-62.8.

14. Morrow WR, Vick W, Nihill MR, Rokey R, Johnston DL, Hedrick TD, Mullins CE. Balloon dilatation of unoperated coarctation of the aorta: short- and intermediate-term results. J Am Coll Cardiol 1988:11:133-138.

15. Beekman RH, Rocchini AP, Dick M, Snider AR, Crowley DC, Serwer GA Spicer RL, Rosenthal A. Percutaneous balloon angioplasty for native coarctation of the aorta. J Am Coll Cardiol 1987;10:1078-1084.

16. Minich LL, Beekman RH, Rocchini AP, Heidelberger K, Bove EL. Surgical repair is safe and effective after unsuccessful balloon angioplasty of native coarc- tation of the aorta. I Am Coll Cardiol 1992;19:389-393.

17. Redington AN, Booth P, Shore DF, Rigby ML. Primary balloon dilatation of coarctation of the aorta in neonates. Br Heart $J$ 1990;64:227-281.

18. Cooper RS, Ritter SB, Rothe WB, Chen CK, Griepp R, Golinko RJ. Angioplasty for coarctation of the aorta: long-term results. Circulation 1987;75:600-604. 19. Marvin WJ. Mahoney LT. Rose EF. Pathologic sequelae of ballon dilation angioplasty for unoperated coarctation of the aorta in children (abstr). $J$ Am Coll Cardiol 1986;7:117A

20. Parikh SR, Hurwitz RA, Hubbard JE, Brown JW, King H, Girod DA. Preoperative and postoperative "aneurysm" associated with coarctation of the aorta. $J$ Am Coll Cardiol 1991;17:1367-1372.

21. Burrows PE, Benson LN, Williams WG, Trusler GA, Coles J, Smallhorn JF, Freedom RM. Iliofemoral arterial complications of balloon angioplasty for systemic obstructions in infants and children. Circulation 1990;82:1697-1704. 